\title{
VALIDATING DFS CONCEPT IN LIFECYCLE SUBWAY PROJECTS IN CHINA BASED ON INCIDENT CASE ANALYSIS AND NETWORK ANALYSIS
}

\author{
Xiaer XIAHOU ${ }^{1}$, Jingfeng YUAN ${ }^{1}$, Qiming LI $^{1^{*}}$, Miroslaw J. SKIBNIEWSKI ${ }^{2}$ \\ ${ }^{1}$ Department of Construction and Real Estate, School of Civil Engineering, Southeast University, \\ 2 Si Pai Lou, Nanjing, 210096, China \\ ${ }^{2}$ Department of Civil and Environmental Engineering, University of Maryland, College Park, MD, 20742, USA
}

Received 15 August 2017; accepted 05 January 2018

\begin{abstract}
Regardless of potential benefits of design for safety (DFS) concept for lifecycle safety management in construction industry, DFS adoption as an early intervention has been slower than expected. While existing research mainly concentrates on construction and operation phases, the role of design phase in construction safety management is always ignored. To validate the influence of DFS concept on lifecycle safety performance, this research conducted an incident case analysis (ICA) based on 442 cases collected from lifecycle subway projects, and a subway design-incident classification model (SDICM) was developed to help identify their relationship to DFS concept. Network theory was applied to study the interdependence of 22 subsystems obtained from China's code for metro design in lifecycle safety performance. Research findings show 236 out of 442 accidents are linked to DFS. Compared with construction phase, operation phase is more susceptible to design work. Station Building (SB), Section Construction (SC), Platform Screen Doors (PSD), Vehicle Systems (VES) and Power Supply Systems (PSS) are identified as having the highest number of accidents. The results of network analysis are consistent with ICA and demonstrate the safety interdependence of subsystems. This research can help improve the cognizance of DFS, and the identified subsystems should be given priority in the design phase.
\end{abstract}

Keywords: safety management, design for safety (DFS), prevention through design (PTD), subway construction, incident case analysis (ICA), network analysis.

\section{Introduction}

The complex and dynamic nature of the construction industry has been widely recognized; therefore, the construction industry has been one of the most hazardous industries in many countries (Zhou et al. 2015). Understanding how accidents occur is fundamental to identifying the main factors and choosing appropriate safety measures (Swuste 2008). As a construction project always starts with planning and design, followed by a construction stage lasting for months or years, and eventually reaching an operation period that lasts for decades before demolition (Zou et al. 2017), decisions made upstream have inherent influences on other stages. Suraji et al. (2001) studied the pattern of construction accident causation, compared with other distal factors, and found that planning and design work are the proximal factors leading to inappropriate site conditions, operative actions and construction operations. Haslam et al. (2005) proposed a hierarchy of causal influences in construction accidents and found that design work is one of the shaping factors that contribute to accidents. Other researchers also found that design work is contributory to lifecycle safety performance in the construction industry (Hinze, Wiegand 1992; Behm 2005; Gambatese et al. 2008). According to the socio-technical systems given by Rasmussen (1997), safety control involves the efforts of government, regulators, associations, etc. Meanwhile, design, construction, and operation companies as well as their staffs are also engaged in the lifecycle construction projects. By conducting the projects, different stakeholders have their own interests. Besides safety, design work should also give consideration for the lifecycle performance of project schedule, cost-efficient, etc. Recently, a breakthrough concept, design for safety (DFS), is considered as a viable intervention to enhance safety management and improve lifecycle performance thereof (Korman 2001; Gambatese, Dunston 2003; Gambatese et al. 2005). The DFS concept

${ }^{*}$ Corresponding author. E-mail: njlqming@163.com 
entails the consideration of lifecycle safety performance at the design phase of construction projects. The designers can mitigate safety hazards by designing barriers, selecting alternative techniques, and increasing the resilience of the project (Hollnagel 2008). Despite its potential benefits, DFS has not been sufficiently adopted within the industry, and barriers may exist in many aspects, such as the absence of legislation in promoting DFS, the fragmentized lifecycle of projects by current procurement methods, and the fear of increases in cost and responsibilities by the designers (Hinze, Wiegand 1992; Gambatese 1998; Gambatese, Hinze 1999; Behm 2005). It is of great importance to validate the link between DFS and incident cases in jobsites and improve the understanding of DFS within the industry.

Subway systems refer to underground or largely underground rail transit systems in urban areas, also known as metro systems, which provide a rapid, economical and clean method of transportation (Fouracre et al. 2003; Wan et al. 2015). Subways have operated in China for 70 years, and the construction of the first subway line in China, Beijing line 1, dates back to the 1950s, entering service in 1971. In fact, there were only a few subway lines under construction or in operation before 2000. Since then, China's government began to investment heavily in subway projects. In the past few decades, a vast number of subway projects have entered service in China, and more subway lines are under construction and planned in many cities (Ding, Zhou 2013). Figure 1 shows the total mileage of subway lines and the cities with subways under construction and in operation from 2000 to 2016 (National Bureau of statistics of China 2016). According to Figure 1, the development of subway projects has accelerated since 2009 , with more subway projects entering service in the following years.

The function of subway systems is the basis of the subway physical system, which is composed of many subsystems built in the construction phase and works in the operation phase, and the dependence and interdependence

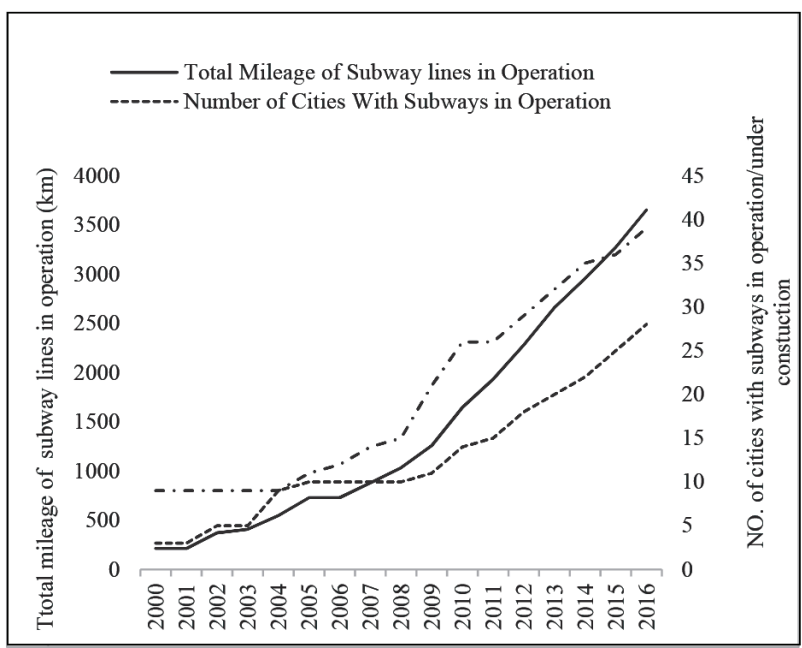

Figure 1. Subways coming into service in Mainland China from 2000 to 2016 of the subsystems make subway physical systems an interconnected network. Incidents occurring in any subsystem during any phase may affect the safety performance of the subway physical system network (SPSN). Safety management in subway projects is not only about the reduction of incidents on jobsites or in service; it is also crucial to the economic development and social stability of society (Deng et al. 2015). While numerous studies have been performed to promote subway safety management in the construction phase (Zou, Li 2010; Ding et al. 2012; Zhou et al. 2011, 2014) and the operation phase (Zhong et al. 2008; Lu et al. 2013; Deng et al. 2015; Zhang et al. 2016), the design phase is often ignored. According to the DFS concept, the best way to improve subway lifecycle safety performance is to have a good understanding of SPSN and design the potential hazards out of SPSN, while understanding the safety performance of each subsystem and their dependence and independence are also conducive to the implementation of DFS.

This paper attempts to validate the DFS concept in subway projects by linking incidents occurring in subway projects to design work and studying the safety performance of subway systems. To achieve this goal, the classification model given by Behm (2005) is improved to study the relationship between 442 collected incidents and design work. Meanwhile, this research also tries to obtain a good understanding of subway physical system safety performance by breaking down the subway system into subsystems according to the Chinese code of metro design. Subsystems and their dependence and independence in subway physical systems will be analyzed using network theory. The results of ICA and network analysis will be discussed. Based on previous findings (Behm 2005), this research tries to extend the validation of DFS concept from the construction phase to the lifecycle of subway projects but also seeks for valuable suggestions. These suggestions can be beneficial for DFS implementation in subway projects, which would consequently improve subway lifecycle safety performance. The structure of this paper is organized as follows: after a brief introduction, an in-depth literature review focused on the concept of DFS and the current status of safety management in lifecycle subway projects is presented. Next, the research approaches of this article, including the research framework, objective and methodology, are illustrated. Afterwards, an incident case analysis is conducted based on 442 incident cases collected from both construction and operation phases of the subway projects. Using the classification model introduced in the former section, incidents related to design work are identified and stored in the subway design-incident database (SDID). These incident cases are analyzed from different perspectives. In addition, the SPSNM is built based on the code for metro design in China. Several parameters of the network, such as degree distribution, closeness, and betweenness, are calculated to study the features of the SPSN. Then, the results of ICA and network analysis are discussed. The contribution of this study and the discussion of future work are presented in the conclusion. 


\section{Literature review}

Design for safety (DFS) is endorsed by the hierarchy of safety management (Manuele 1997), since design phase upstream determines the workplace and work methods that are effective in avoiding, eliminating and controlling risks. Furthermore, according to the time/safety influence curve given by Szymberski (1997), the ability to influence lifecycle safety will decrease as the projects move forward. While safety management is traditionally conducted in the construction or operation phases, and accidents are involuntarily considered as the responsibility of contractors or operators, DFS as well as other expressions (i.e., prevention through design, safety through design, design for construction worker safety) entails the involvement of designers, architects and engineers (DAEs) in safety management during their work (Taiebat, Ku 2011). Although the designers' influence on workers safety has been realized, the implementation of DFS is impacted by numerous factors (Rasmussen 1997; Gambatese et al. 2005), and the absence of designers' roles in construction project lifecycle safety management has been identified by scholars during the past few decades (Hinze, Wiegand 1992; Gambatese, Hinze 1999; Gibb 2002). Previous researches have shown that current contract model has separated design phase from construction and operation phase, and hindered the adoption of DFS (Gambatese 1998). The separation lead to divergence in various aspects, for example, the designers are fear of liabilities and would not like to get involved in the safety in jobsites (Hinze, Wiegand 1992). Gambatese et al. (2005) found that the culture of the construction industry also precludes the designers from addressing safety management in the design phase. In a construction project, the quality, cost, and schedule are major concerns for design companies, and considerable efforts are made to these aspects instead of safety (Gambatese et al. 2005). In addition, while DFS has gradually attracted the interests in construction industry, the shortages of available tools and the safety knowledge of the designers and their companies likewise hinder the implementation of DFS. To promote DFS in the construction industry and increase the designers' involvement in lifecycle safety management, regulations in different countries and regions have been established to address the designers' liabilities, with the most representative regulation in the United Kingdom's construction (design and management) regulations, which place responsibility on the DAEs (MacKenzie et al. 2000; Gambatese et al. 2005; Martínez-Aires et al. 2015). Instead of the legislation, Tymvios and Gambatese (2016) argue that the owners should be the targeted group in construction industry, and business case method could generate the owners' interests to adopt DFS. At the same time, the needs for the improvement of designer hazard recognition skill are also urgent (Hallowell, Hansen 2016). Advanced technologies like databases, expert systems, virtual reality, BIM, etc. are employed to help designers apply DFS in their work. Numerous tools (e.g., Design for safety toolbox, T-export, Construction Hazard Assessment Implica- tion Review) have been developed to assist the designers in the design phase (Gambatese et al. 1997; Gambatese, Hinze 1999; WorkCover 2001; Hadikusumo, Rowlinson 2004; Carter, Smith 2006; Qi et al. 2011). To demonstrate links between design work and incidents on the jobsite, Gibb et al. (2004) studied 100 cases and found that 47\% could have been avoided if given consideration in the design phase. To make the link between construction fatalities and DFS concept more clear, Behm (2005) investigated 224 fatalities and found that $42 \%$ had root causes in design, and this result was further evidenced by an expert panel (Gambatese et al. 2008). Driscoll et al. (2008), using the Australian National Coroners' Information System as a data source, found that design is a significant contributor to work-related fatal injuries in Australia. Meanwhile, the positive influence of DFS has also been proven by some pilot construction projects (Weinstein et al. 2005). Currently, most research focuses on the construction phase, and the influence of DFS on the operation phase must be studied.

Safety management in subway projects has been an important issue due to its great significance on social economy and public safety. However, the complexity of subway physical systems and the harsh environment within their lifecycle make it impossible to settle the safety risks once and for all. Currently, safety management in subway projects is divided by different phases or subsystems. Zou and Li (2010) developed a risk access method by combining a risk checklist and fuzzy analytic hierarchy process (FAHP) for subway construction, and Ding and Zhou (2013) developed a web-based system for safety risk early warning in an urban metro construction phase. Zhang et al. (2014) proposed a fuzzy decision analysis method for safety management in tunnel construction. Research can also be found in the operation phase (Wang et al. 2007; Lu et al. 2011, 2013; Deng et al. 2015). Research has also focused on subsystems such as fire evacuation systems (Zhong et al. 2008), ventilation systems (Li, Chow 2003), etc. In an observation study, Coats and Walter (1999) noted that designing a proper pit in a station design will reduce the risk of injury or death after a fall or jump under a train. Realizing the influence of design work in subway safety management, Seo and Choi (2008) introduced the concept of safety impact assessment to achieve DFS and devised a safety impact assessment model in a ground subway project. Ding et al. (2012) developed a safety risk identification system (SRIS) for subway construction based on construction drawings; SRIS aims to assess pre-construction safety risks after the design work is complete. Reducing or eliminating lifecycle safety risks upstream in the design has been a common trend with great potential in subway projects.

To summarize, the DFS concept has been theoretically considered as a breakthrough idea with great potential in construction safety management, including subway projects. Currently, few studies have reported on the influence of DFS on the lifecycle of construction projects, especially on the operation phase. Its influences and ben- 
efits should be further confirmed by evidence from the frontline. In addition, the complexity of subway physical systems has hindered the adoption of DFS. The dependence and interdependence of different subsystems in lifecycle safety management still remain ambiguous, which makes DFS implementation adoption difficult. Incident case analysis (ICA) has been widely used for construction safety management (Hinze 1997), and incidents occurring in a subway lifecycle contain abundant information that has been frequently used for safety promotion (Zhou et al. 2011; Zhang et al. 2016). While ICA is an empirical approach that studies incidents that occurred in the past, network theory provides an useful tool to model subway physical systems as a network and learn the dependence and interdependence of its subsystems in lifecycle safety performance (Deng et al. 2015). This paper combines these two methods to validate the DFS concept in subway projects and help improve the understanding of subway design work in lifecycle safety management.

\section{Research approach}

\subsection{Research framework}

The outline of this research framework can be illustrated by Figure 2. This research conducted subway safety management from two aspects. First, ICA makes use of accident cases as a resource to investigate the causalities. To improve the efficiency and accuracy of the classification process, the subway design-incident classification model (SDICM) was developed to identify incident cases' relationship to the DFS concept. After classified by SDICM, DFS-related cases were obtained and stored in the subway design-incident database (SDID) for further analysis. Second, instead of studying incident cases one by one, network analysis regards a subway physical system as an entire network. Based on network theory, a subway physical system network model (SPSNM) was built, and network analysis software was employed to analyze the model. By studying the characteristics of the subway physical system network (CSPSN), the dependence and interdependence of subsystems in a subway lifecycle safety performance were identified. Finally, the results from the two aspects will be analyzed and discussed to validate the DFS concept, and suggestions were offered for subway safety design.

\subsection{Objective and scope}

By studying the incident cases and the relationship of subsystems in an SPSN, this research will help to obtain a better understanding of the influence of design work on subway lifecycle safety management and validate the concept of DFS in subway projects, which is crucial to the implementation of DFS. To achieve the goals of this paper, several principles were critical during the data collection and analysis: first, despite numerous contributory factors to the incidents, only cases related to DFS will be identified and discussed in this research. Second, designers' work will be influenced by numerous factors, and design errors may result from lapse, slips, and mistakes of designers (Lopez et al. 2010), but this paper will not focus on reasons that led to a design failure.

\section{Methodology}

\subsection{Subway design-incident classification}

Incidents cases frequently reported in the construction industry contain abundant information and ICA has been employed as an effective way to improve safety management. Accidents can be classified in various ways and for different purposes (Lortie, Rizzo 1998). Motivated by the objective of this paper, the subway design-incident classification model (SDICM) was developed, as seen in Figure 3, to investigate the cases. According to the reverse pyramid theory, accidents occurring in jobsites are only the tip of the iceberg, and precursors are critical events in the evolutionary process of an accident (Kyriakidis et al. 2012). By studying precursors, the causality of accidents can be identified.

In this paper, several investigation criteria developed by Behm (2005) were adopted to help classify cases. The feasibility of these criteria in linking cases to design for safety concept has been validated (Gambatese et al. 2008). Errors generate chains of structured events within the sociotechnical system (Turner 1989), it is complicate and

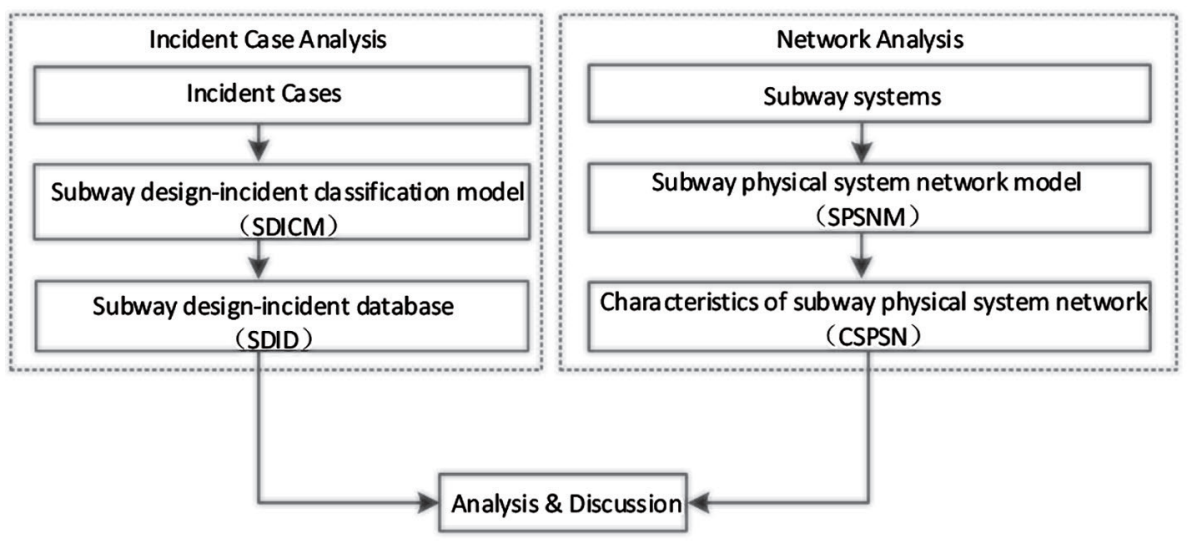

Figure 2. Research framework 


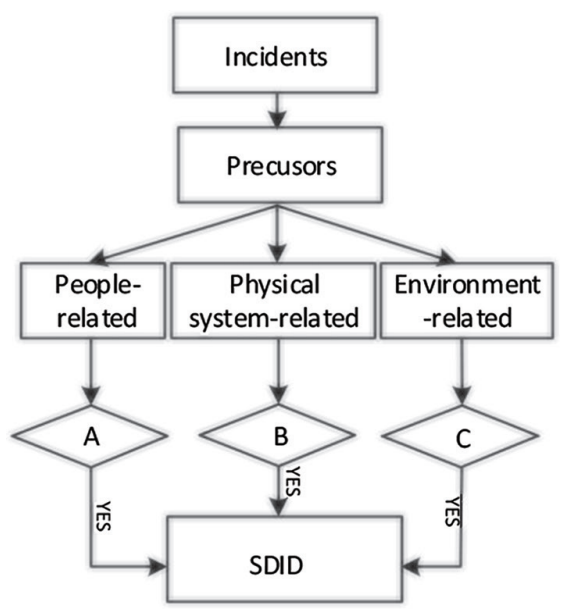

Figure 3. Subway design-incident classification model (SDICM)

time-consuming to find the causations of accidents. To improve the efficiency and accuracy of the classification, incidents were first divided into three categories (i.e., people-related, physical systems-related, or environment-related) according to their direct causations (Lu et al. 2013). As some accidents had more than one precursor, they were studied under the most relevant category. Then, the investigation criteria provided by Behm (2005) were applied; if any of the incidents meet one of the criteria, the incident can be linked to the DFS concept and stored in the SDID. The criteria are as follows: A: Are there any suggestions, if implemented during the design process, which would improve the individuals' awareness of the risk and ability to avoid the risk, and finally prevent or mitigate the accidents led by people-related factors? B: Are there any measures, if implemented during the design process, which would enhance the safety performance of the failed physical system, and finally eliminate or mitigate the accidents led by physical system-related factors? C: Is it possible to improve the hazardous circumstance that led to the accident during the design phase, and finally prevent or mitigate the accidents led by environment-related factors?

\subsection{Network analysis}

SPSNs contain numerous subsystems, and one incident does not often solely occur. Safety hazards or failures of one subsystem may interact with an existing sociotechnical structure and finally result in a sequence of incidents (Turner 1989). Instead of modelling by structural deposition of the tasks, network analysis provides a systematic view of subway physical systems by functional abstraction of SPSNs, and features of SPSNs can be explored according to network theory. Network analysis is a powerful tool to study the dependence and interdependence of the subsystems in subway lifecycle safety performance. The graph of the network always constitutes a number of vertices and edges. In an SPSN, vertices represent different subsystems in the SPSN, while their relationship in safety performance can be abstracted as the edges in the graph. As the safety performance of one subsystem is affected

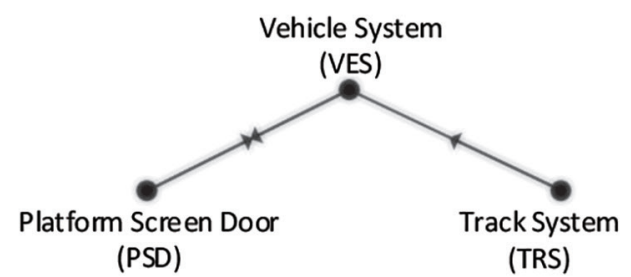

Figure 4. Example of network analysis

by others, the arrows of the edges imply that the vertex at the end is influenced by the vertex in the front, that is, the arrow reflects the direction of safety performance interaction of two subsystems at the two ends. This can be illustrated as Figure 4, where failures of the Platform Screen Door subsystem and Vehicle System may affect each other directly, for example, when the vehicle stops in the subway station; if the doors of the vehicle and platform screen cannot work synchronously, the safety of passengers as well as subway systems will be threatened. Thus, the edge between VES and PSD has two arrows in both directions. Incidents occurring within VES rarely influence the Track system (TRS); on the contrary, TRS is fundamental to VES. Therefore, the edge between VES and TRS has one arrow, and the direction of the arrow is from TRS to VES. Incidents occurring in PSD or TRS will not affect each other directly; thus, there is no edge between these two subsystems.

\section{Incident case analysis}

\subsection{Data collection}

Unfortunately, the lifecycle of subway projects is always accompanied by incidents. By analyzing these incidents, the results provide abundant information for safety management improvement. Due to the time duration, regional distribution and the confidentiality of subway construction and operation companies, it was impossible for the authors to obtain detailed incident reports from the government or the companies. Instead, in this research, accidents were updated from literature and media (including internet, TV, and newspapers) based on continuous researches (Zhou et al. 2011; Wan et al. 2015; Zhang et al. 2016). In the data collection, incidents happened to construction workers and who are engaged in operation, maintenance are included in the database. Meanwhile, DFS concept also stresses lifecycle performance of projects. As in subway projects, incidents led by the failure of subway physical system during the operation phase are also included. Since DFS concept is not a panacea (Behm 2005), accidents caused by the errors of passengers are not included and discussed. For example, the case that one passenger jumped on the rail and suicided in Beijing subway line 1 , on $24^{\text {th }}$ Feb, 2014 is not included. In this paper, up to the end of 2014, 442 cases were compiled from mainland China. Among them, 216 cases were obtained from the construction phase and the other 226 cases were from the operation phase. The figures of these incidents 
Table 1. Statistics of the collected subway incidents in China from 1971 to 2014

\begin{tabular}{|lcccccc|}
\hline & \multicolumn{2}{c}{ Construction phase } & \multicolumn{2}{c|}{ Operation phase } & Total \\
\cline { 2 - 5 } Type of incident & Casualties & Non-casualties & Casualties & Non-casualties & \\
\hline $\begin{array}{l}\text { Num. of incident } \\
\text { total }\end{array}$ & 123 & 93 & 49 & 226 & 177 \\
\hline
\end{tabular}

are listed in Table 1. In the incident cases, at least 744 casualties were reported in 172 incidents (123 in the construction period and 49 in the operation period), with 198 deaths and 546 injuries. The number of collected incidents shows no obvious difference between the construction and operation periods. Table 1 shows that more incidents lead to casualties in the construction period than in the operation period. It is common that failures in the operation stage are always reported with other types of loss, such as traffic paralysis and substantial economic losses.

Figure 5 illustrates the distribution of 419 incidents occurring from 2000 to 2014. In the collected incidents, 19 cases occurred before 2000 and were scattered throughout the 30 years from 1969 to 1999, and four cases without accurate year information were not included in Figure 5. As illustrated in Figure 5, from 2000 to 2009, subway accidents increased gradually within the ten years, and incidents during the construction phase held the leading position. After 2010, the total number of accidents in the construction phase starts to decrease, while more accidents were reported in the operation stage. Compared to the growth of both subway lines in operation and under construction shown in Figure 1, Figure 5 reflects an improvement of safety management in the construction phase since 2010, and this can also be evidenced in the statistics of the following years in Figure 5. The number of accidents occurring in the operation phase grew in pace with the increase of subway lines that came into service during this period; meanwhile, the increasing subway lines made the subway system more complex and vulnerable during the operation phase (Deng et al. 2015). After 2010, the total number of incidents began to drop off, and incidents in the operation stage were more frequently reported than the construction phase. It can be concluded that the safety experience accumulated before 2009 was helpful in eliminating risks and

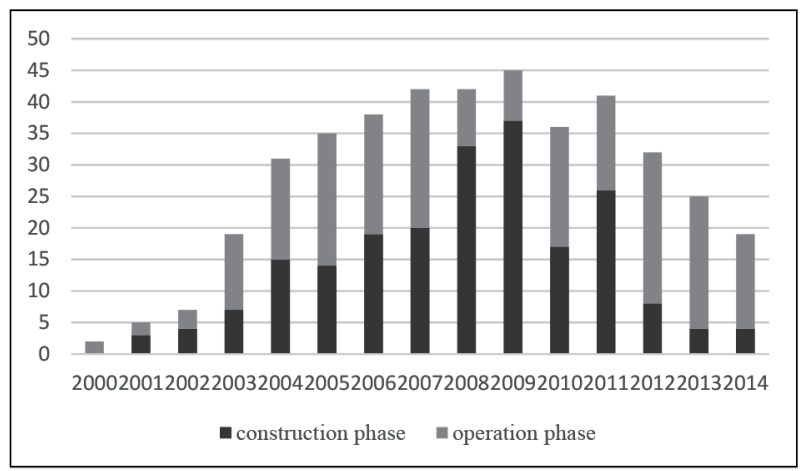

Figure 5. Statistics of total accidents by years improving subway lifecycle safety performance, and more attention should be paid to the operation period.

Based on the ICA above, the collected data accurately reflect the situation of subway lifecycle safety management in mainland China. The collected incident cases are valid for further analysis in this research.

\subsection{Data classification}

During the data analysis process, the collected incident cases were reviewed one by one using SDICM. The first step was to determine the direct causes of the incidents according to three given precursors; then, the classification criteria were applied to investigate the relationship between incident cases and the DFS concept. If any answer to the criteria was affirmative, its link to DFS was confirmed, and these incidents were stored in SDID for further analysis. In contrast, if all the answers were negative, the incident was not linked to DFS. The data classification process was conducted by members of the research team which has conducted lifecycle safety management of subway projects over ten years. Table 2 shows examples of the incident case classification process.

\subsection{Incident case analysis}

After being classified by the subway design-incident classification model (SDICM), 236 out of 442 (53.3\%) incident cases were identified to be DFS-related - 78 cases (36.1\%) in the construction phase and 158 cases (69.9\%) in the operation phase, as shown in Figure 6. A total of 124 incidents were reported with 554 casualties in total, with 196 casualties in the construction phase and 358 casualties in the operation phase respectively, as shown in Figure 7. Figures 6 and 7 demonstrated that the design phase had a greater influence on the operation phase than the construction phase, no matter whether it was calculated by the number of incidents or the number of casualties. The main reason for this phenomenon is that the purpose of subway design is for subway operation, thus more design activities are focused on the operation phase. This can also be understood by the time duration of different stages: subway projects are always under construction for years, but the operation period may last for decades. In addition, design work only affects the construction-related persons in the construction phase, while the influence of design work on people dramatically increases due to masses of individuals (e.g., staffs and passengers) involved in the subway operation phase. 
Table 2. Three examples of incident case classification process

\begin{tabular}{|c|c|c|c|c|c|c|c|}
\hline NO. & City & Phase & Description of accidents & Precursor & $\begin{array}{l}\text { Involved } \\
\text { Subsystem }\end{array}$ & $\begin{array}{l}\text { Adoptable design } \\
\text { measures to avoid } \\
\text { the accident }\end{array}$ & $\begin{array}{l}\text { DFS- } \\
\text { related or } \\
\text { not }\end{array}$ \\
\hline 1 & Nanjing & Construction & $\begin{array}{l}\text { At } 6: 00 \text { am on February } 5^{\text {th }} 2007 \text {, ground } \\
\text { collapse occurred due to water damage } \\
\text { in the project of Nanjing Subway Line } \\
\text { 2, to the north of Hanzhong Road and } \\
\text { Pailou Lane intersection. Then, ground } \\
\text { collapse triggered a pipeline rupture, } \\
\text { following by gas leakage and explosion. } \\
\text { Part of the Jinpeng Building was burned. } \\
\text { No one was killed or injured in the } \\
\text { accident. }\end{array}$ & $\begin{array}{l}\text { Environment- } \\
\text { related }\end{array}$ & $\begin{array}{l}\text { Subway } \\
\text { section(SC) }\end{array}$ & $\begin{array}{l}\text { Modify the design } \\
\text { of precipitation well } \\
\text { and waterproof } \\
\text { curtain before } \\
\text { construction } \\
\text { would reduce the } \\
\text { possibility of water } \\
\text { damage }\end{array}$ & DFS-related \\
\hline 2 & Shanghai & Operation & $\begin{array}{l}\text { On July } 15^{\text {th }} 2007 \text {, a man was nipped by } \\
\text { doors of the platform and the train, and } \\
\text { died when subway train started to leave } \\
\text { the station. }\end{array}$ & $\begin{array}{l}\text { Physical } \\
\text { system- } \\
\text { related; } \\
\text { People-related }\end{array}$ & $\begin{array}{l}\text { Platform } \\
\text { screen } \\
\text { door(PSD) }\end{array}$ & $\begin{array}{l}\text { Design a reliable } \\
\text { system to } \\
\text { synchronize the } \\
\text { operation of PSD } \\
\text { and train doors }\end{array}$ & DFS-related \\
\hline 3 & Shenzhen & Construction & $\begin{array}{l}\text { On the morning of Sept. } 7^{\text {th }} 2010 \text {, a } \\
\text { sudden rain led to the electric leakage of } \\
\text { the equipment, and one worker received } \\
\text { a lethal electric shock. }\end{array}$ & $\begin{array}{l}\text { Environment; } \\
\text { Physical- } \\
\text { related; } \\
\text { system-related }\end{array}$ & $\begin{array}{l}\text { Station } \\
\text { Building } \\
\text { (SB) }\end{array}$ & No & No \\
\hline
\end{tabular}

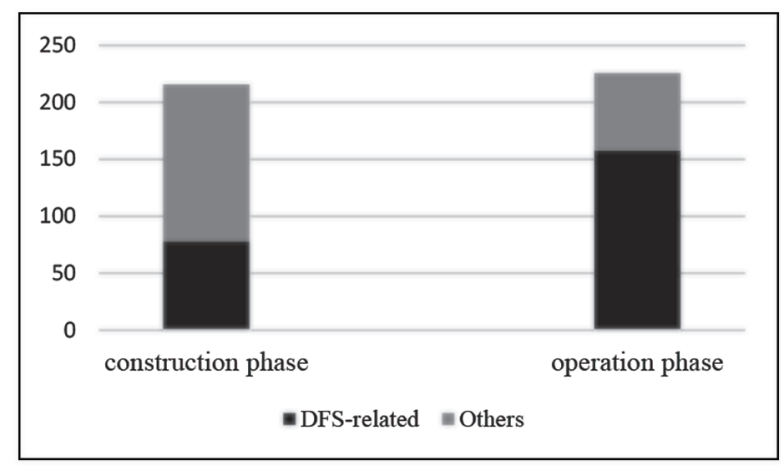

Figure 6. Statistics of incidents by phases

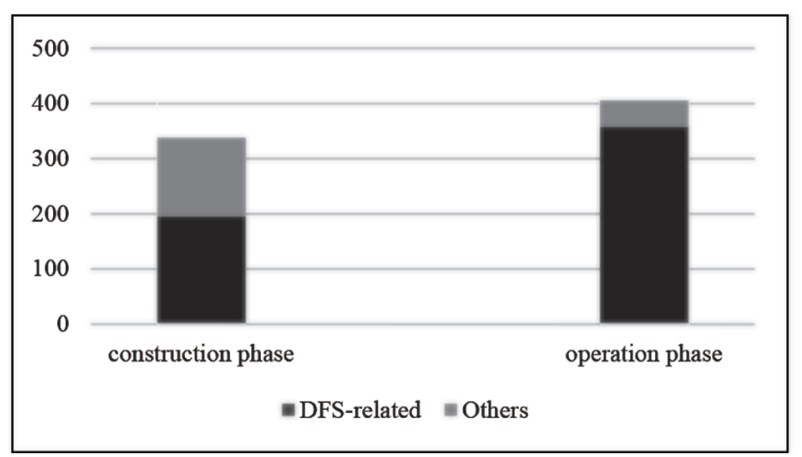

Figure 7. Statistics of incidents by casualty

Subsystems in the subway are built in the construction phase and work in the operation phase. The construction quality and safety performance of each subsystem determines the function of the entire system. Failures that occur in one subsystem not only result in reduction or loss of its own function but also affect the entire system due to their interdependence. To ensure the stable function of the entire system, it is of great importance to identify the subsystem with a high accident rate. In this research, China's Code for Metro Design was used to classify and explore the feature of subway design work in China. There are 29 chapters in the design code, including general provisions, terms, operation organization, gauges, requirements for disaster prevention, environment protection, and 23 other subsystems. To obtain a better understanding of the subsystems, two subsystems (Elevated structure, Underground structure) are consolidated as section construction. The final 22 subsystems and the abbreviations are listed in Table 3.

Both the 442 collected incident cases and 236 DFSrelated cases were classified by the 22 subsystems. The failure or absence of one subsystem, which directly led to an incident, was identified. A group of 46 cases among all the cases and 2 DFS-related cases were excluded due to missing information regarding the subsystems. Figure $8 \mathrm{dem}$ onstrates the relative number of collected incidents classified by each subsystem, both in total cases and DFS-related cases. Station Buildings (SB) and Section Construction (SC) ranked first and second among the statistics of all cases. SB and SC are the fundamental physical space for other subsystems, and the construction of these two subsystems is hazardous due to the uncertainty of geological and hydrological conditions. Considerable incidents also occurred within the Platform Screen Door (PSD), Vehicle System (VES), and Power Supply System (PSS), where PSD is a critical physical protection for individuals in the platform, VES is the direct carrier in the transportation system, and PSS supplies the entire subway physical system with power. In DFS-related cases, PSD had the same number of accidents as in total cases, indicating that all of the incidents occurring in PSD were related to the design phase; The design of PSD helps to build barriers to prevent 
Table 3. modified subsystems and their abbreviations in China’s code for metro design

\begin{tabular}{|clcclll|}
\hline Num. & \multicolumn{1}{c}{ Name of the subsystems } & Abbr. & Num. & Name of the subsystems & Abbr. \\
\hline 1 & Vehicle system & VES & 12 & Signal system & SIS \\
2 & Line system & LIS & 13 & Automation fare collection system & AFCS \\
3 & Track system & TRS & 14 & Automation fire alarm system & AFAS \\
4 & Subgrade system & SUS & 15 & Integrated supervisory and control system & ISCS \\
5 & Station building & SB & 16 & Building automatic system & BAS \\
6 & Section construction & SC & 17 & Passenger information system & PIS \\
7 & Engineering waterproof & EWP & 18 & Access control & AC \\
8 & Ventilation Air-conditioning and Heating & VAH & 19 & Operation control center & OCC \\
9 & Water supply and drainage & WSD & 20 & Equipment in station for passengers & ESP \\
10 & Power supply system & PSS & 21 & Platform screen door & PSD \\
11 & Communication system & COS & 22 & Base for the vehicle & BV \\
\hline
\end{tabular}

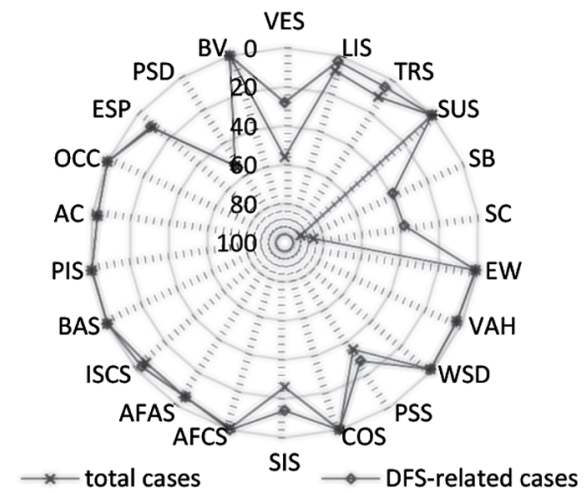

Figure 8. Incidents classified by subsystems

the happening of unwanted events (Hollnagel 2008) like falling off the platform, thus, by designing an effective and reliable PSD system, the hazards could be reduced dramatically (Krysinska, De Leo 2008). Although the percentages of their links to DFS are lower than other subsystems, DFS adoption in SB and SC is also meaningful for lifecycle safety management of subway projects since the total number of accidents occurred in SB and SC made up a larger proportion of the incidents among the total incidents.

\section{Network analysis}

\subsection{Subway physical system network model}

A subway physical system is a complex network composed of various subsystems, and there is no classification standard for a subway physical system. In this article, China's code for subway design mentioned above can help obtain a general understanding of the subway physical system. Meanwhile, network analysis is an effective tool for studying the features of the SPSN. In this paper, Pajek, version 5.01, was employed to study the CSPSN. A total of 22 sorted subsystems were used as the vertices, and their interdependence in safety performance represented the edges in SPSN. Delphi Method was employed to study the interdependence of subsystems in safety performance. According to Hallowell and Gambatese (2009), the proper number of the Dephi panel would be eight to 12 members. In this paper, the Delphi survey was conducted among 10 experts of this field in Nanjing and Shanghai where numerous subway lines are in operation and under construction. The expert panel constitutes of three professional engineers from a subway design company of different disciplines, one construction site manager and one site safety manager from a subway construction company, two high ranking senior officers and one maintenance worker from an operation company. Two researchers of this field are also included to reduce the subjective of the interviews. The experts were asked about their opinions about the interdependence of subsystems in safety performance. After three round questionnaire survey, the panel reached a good consensus. The results were recorded and transcribed into a matrix shown as Table 4 . In the matrix, if the subsystem in the column is affected directly by subsystems in the row, the value would be listed as 1 , otherwise the value is 0 , which means there are no direct interactions between the two subsystems. For example, the safety performance of the Track System (TRS) has a direct influence on the Vehicle System (VES), and the value of the third row in the first column is 1 .

This matrix was then translated into a Pajek input file. After running by Pajek, 22 vertices and 47 lines were obtained. The centrality of the network explains the number of vertices that one can reach within certain distances and the centered vertex stands between others on the path of the communication (Bavelas 1948). The interdependence subsystems in the subway physical system can be learned by studying the centrality of the network. In this research, Pajek was employed to calculate the following three parameters, which reflect the centrality of the SPSN: degree distribution, closeness, and betweenness. These three parameters reveal the relationship and interdependence of different subsystems in SPSN. Figure 9 shows the topology of SPSN in safety management drawn by Pajek. 
Table 4. Matrix of the interdependence of subway subsystems

\begin{tabular}{|c|c|c|c|c|c|c|c|c|c|c|c|c|c|c|c|c|c|c|c|c|c|c|}
\hline & $\stackrel{n}{>}$ & $\cong$ & $\stackrel{\mathscr{A}}{\mathscr{H}}$ & $\tilde{D}$ & ڤै & un & 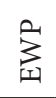 & $\underset{>}{\stackrel{T}{4}}$ & 帘 & $\tilde{n}$ & $\tilde{o}$ & $\ddot{\omega}$ & $\begin{array}{l}\text { Y } \\
\text { 至 }\end{array}$ & 衰 & $\begin{array}{l}\mathscr{y} \\
\mathscr{D}\end{array}$ & 乐 & $\stackrel{\Omega}{\Omega}$ & U & $\begin{array}{l}\text { U } \\
\text { O }\end{array}$ & 岕 & مि & $\vec{m}$ \\
\hline VES & - & 0 & 0 & 0 & 0 & 0 & 0 & 0 & 0 & 0 & 0 & 0 & 0 & 0 & 0 & 0 & 0 & 0 & 0 & 0 & 1 & 1 \\
\hline LIS & 0 & - & 0 & 1 & 1 & 1 & 1 & 0 & 0 & 0 & 0 & 0 & 0 & 0 & 0 & 0 & 0 & 0 & 0 & 0 & 0 & 0 \\
\hline TRS & 1 & 0 & - & 0 & 0 & 0 & 0 & 0 & 0 & 0 & 0 & 0 & 0 & 0 & 0 & 0 & 0 & 0 & 0 & 0 & 0 & 0 \\
\hline SUS & 1 & 0 & 1 & - & 0 & 0 & 1 & 0 & 1 & 0 & 0 & 0 & 0 & 0 & 0 & 0 & 0 & 0 & 0 & 0 & 0 & 0 \\
\hline SB & 1 & 0 & 1 & 1 & - & 1 & 1 & 1 & 1 & 1 & 1 & 1 & 1 & 1 & 1 & 1 & 1 & 1 & 0 & 1 & 1 & 0 \\
\hline SC & 1 & 0 & 1 & 1 & 1 & - & 1 & 1 & 1 & 1 & 1 & 1 & 0 & 1 & 0 & 0 & 0 & 0 & 0 & 0 & 0 & 1 \\
\hline EWP & 0 & 0 & 0 & 1 & 1 & 1 & - & 0 & 1 & 1 & 1 & 1 & 0 & 0 & 0 & 0 & 0 & 0 & 1 & 1 & 0 & 1 \\
\hline VAH & 1 & 0 & 1 & 0 & 0 & 0 & 1 & - & 0 & 1 & 1 & 1 & 0 & 1 & 0 & 0 & 0 & 0 & 0 & 1 & 0 & 0 \\
\hline WSD & 0 & 0 & 0 & 1 & 1 & 1 & 1 & 1 & - & 1 & 0 & 0 & 0 & 0 & 0 & 0 & 0 & 0 & 0 & 0 & 0 & 1 \\
\hline PSS & 1 & 0 & 0 & 0 & 0 & 0 & 1 & 1 & 1 & - & 1 & 1 & 1 & 1 & 1 & 1 & 1 & 1 & 1 & 1 & 1 & 1 \\
\hline $\cos$ & 1 & 0 & 0 & 0 & 0 & 0 & 0 & 0 & 0 & 0 & - & 1 & 1 & 1 & 1 & 1 & 1 & 1 & 1 & 1 & 1 & 0 \\
\hline SIS & 1 & 0 & 0 & 0 & 0 & 0 & 0 & 0 & 0 & 0 & 1 & - & 0 & 0 & 0 & 1 & 0 & 0 & 1 & 0 & 1 & 0 \\
\hline AFCS & 0 & 0 & 0 & 0 & 0 & 0 & 0 & 0 & 0 & 0 & 0 & 0 & - & 0 & 0 & 0 & 1 & 1 & 0 & 0 & 0 & 0 \\
\hline AFAS & 1 & 0 & 1 & 0 & 0 & 0 & 0 & 0 & 0 & 1 & 1 & 1 & 1 & - & 0 & 1 & 0 & 0 & 1 & 1 & 0 & 1 \\
\hline ISCS & 1 & 0 & 0 & 0 & 0 & 0 & 0 & 0 & 0 & 0 & 0 & 0 & 0 & 1 & - & 0 & 1 & 1 & 0 & 1 & 1 & 0 \\
\hline BAS & 1 & 0 & 1 & 1 & 0 & 0 & 1 & 1 & 1 & 0 & 0 & 0 & 0 & 1 & 0 & - & 0 & 0 & 0 & 0 & 0 & 0 \\
\hline PIS & 0 & 0 & 0 & 0 & 0 & 0 & 0 & 0 & 0 & 0 & 0 & 0 & 0 & 0 & 0 & 0 & - & 1 & 0 & 0 & 0 & 0 \\
\hline AC & 0 & 0 & 0 & 0 & 0 & 0 & 0 & 0 & 0 & 0 & 0 & 0 & 0 & 0 & 0 & 0 & 0 & - & 1 & 1 & 1 & 1 \\
\hline OCC & 1 & 0 & 0 & 0 & 0 & 0 & 0 & 0 & 0 & 1 & 1 & 1 & 0 & 0 & 0 & 0 & 0 & 0 & - & 0 & 1 & 1 \\
\hline ESP & 0 & 0 & 0 & 0 & 0 & 0 & 0 & 0 & 0 & 0 & 0 & 0 & 0 & 0 & 0 & 0 & 0 & 1 & 0 & - & 0 & 0 \\
\hline PSD & 1 & 0 & 0 & 0 & 0 & 0 & 0 & 0 & 0 & 0 & 0 & 0 & 0 & 0 & 0 & 0 & 0 & 1 & 0 & 0 & - & 0 \\
\hline BV & 1 & 0 & 0 & 0 & 0 & 0 & 0 & 0 & 0 & 0 & 0 & 0 & 0 & 0 & 0 & 0 & 0 & 0 & 0 & 0 & 0 & - \\
\hline
\end{tabular}

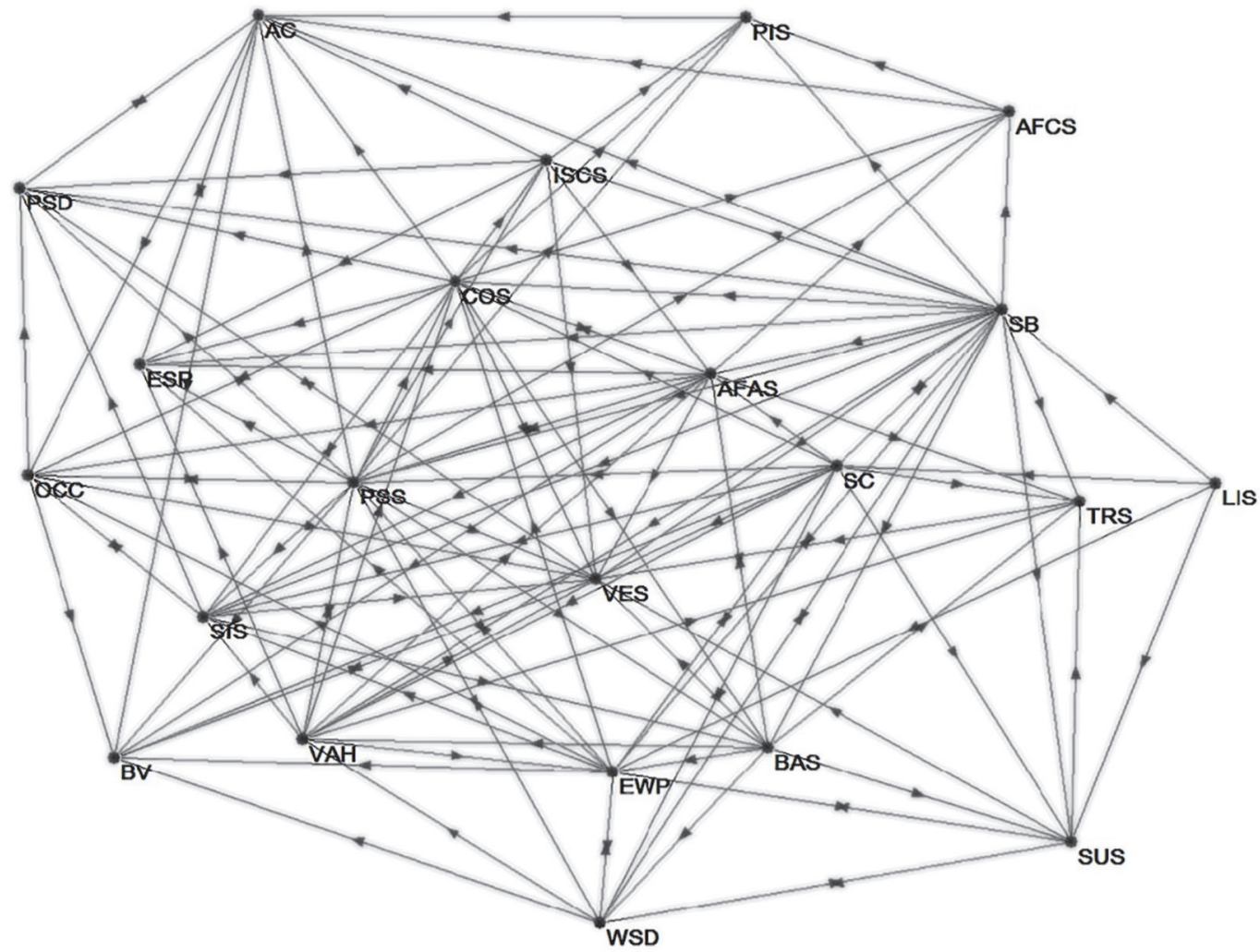

Figure 9. The topology of SPSN in safety management 


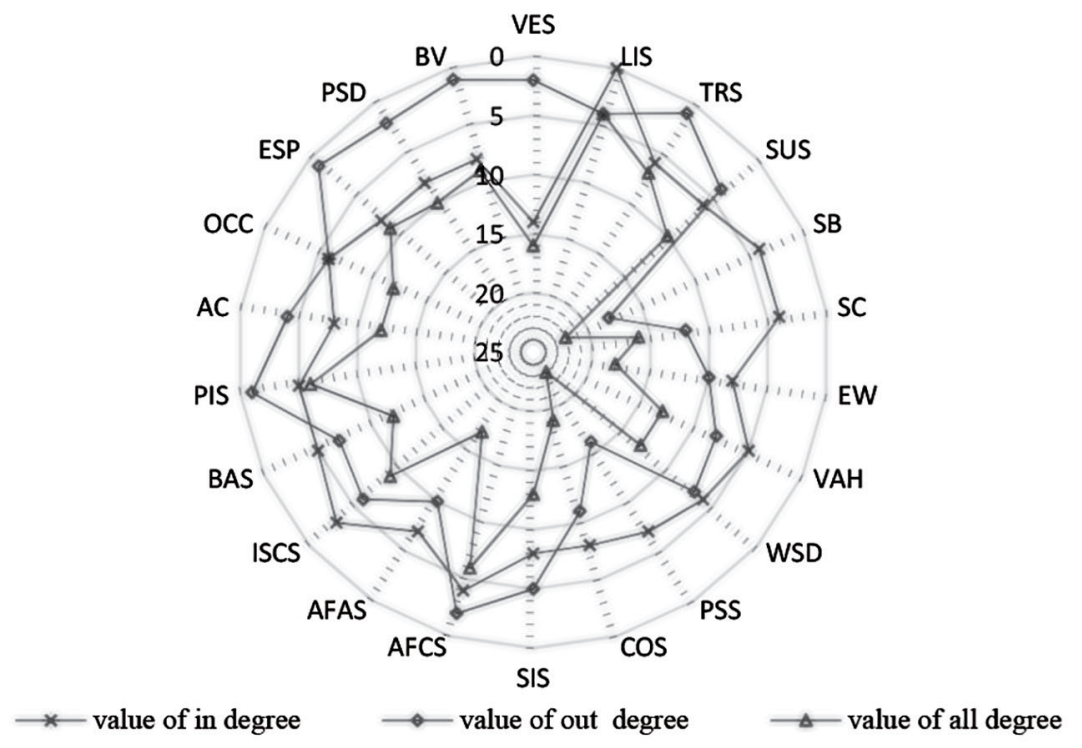

Figure 10. Degree distribution of SPSN

\subsection{Degree distribution}

The degree of a network represents the number of edges connected to a node. According to the direction of edges linked to a node, the degree is divided as in degree, out degree, and all degree. The average degree of the network is 12.55 , indicating that each subsystem is connected to 12 or 13 other subsystems in the entire network. The degree distribution is calculated and shown in Figure 10; Power Supply System (PSS) has the highest all degree value of 23, followed by Station Building (SB), Communication System (COS), Automation Fire Alarm System (AFAS), and Vehicle System (VES), which means these five subsystems have relatively higher interdependence with other subsystems. VES has the highest in degree with a value of 14 . In the network, there are 14 paths leading to VES, which means the safety performance of VES is affected directly by 14 other subsystems. Since the main purpose of the

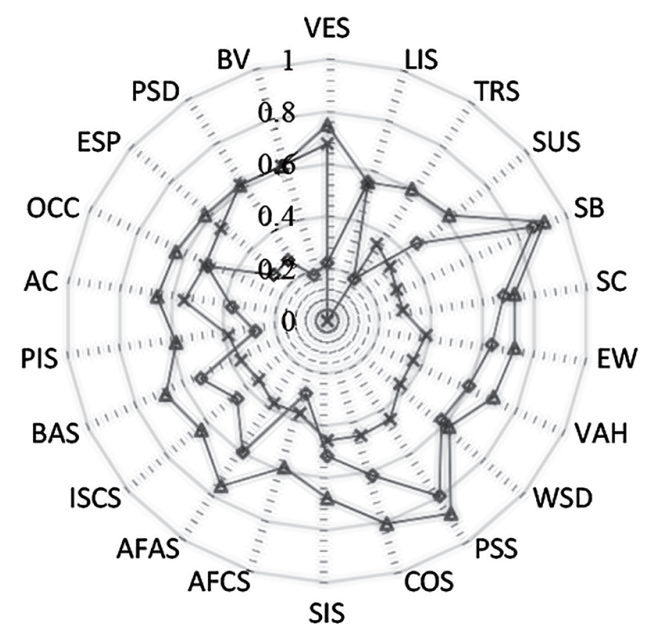

$\rightarrow$ in closeness $\multimap$ out closeness $\triangle$ all closeness

Figure 11. Values of in closeness, out closeness and all closeness subway system is to transfer passengers to their destination, VES, as the main container, can be considered as the terminal of the subway system. Any failure in the subway physical system will lead to loss of its terminal function. SB has the highest out degree with a value of 18 , which means that failures in SB may affect 18 other subsystems directly. In an SPSN, SB is the intersection of different subsystems and the main space for passengers and other activities. Safety management in SB is considered crucial for the entire network.

\subsection{Closeness}

The value of closeness determines the centrality of a vertex in a network by calculating the sum of its geodesic distance from other vertices (Sabidussi 1966), and a vertex with higher closeness value is closer to all other vertices in the network. Figure 11 depicts the closeness of SPSN. Station Building (SB) and Power Supply System (PSS) ranked the highest closeness among all the vertices, which indicates that SB and PSS are in the center of the network, and these two subsystems hold a crucial position in the safety performance of subway physical systems. SB also has the highest out closeness value of approximately 0.80 , which denotes that SB has the greatest influence on the entire subway physical system. Vehicle System (VES) has the highest in closeness value of approximately 0.68 , which indicates that it is more easily affected by other subsystems. The results of closeness are in accordance with the degree distribution.

\subsection{Betweenness}

Betweenness is another parameter to verify the centrality of a network. The node betweenness centrality is illustrated as Figure 12. Access Control (AC), Operation Control Center (OCC) and Power Supply System (PSS) are the top 
Table 5. Top 5 subsystems of three parameters in network analysis

\begin{tabular}{|c|c|c|c|c|c|c|c|c|c|c|}
\hline \multirow[t]{2}{*}{ Rank } & \multirow{2}{*}{$\begin{array}{c}\text { Degree } \\
\text { distribution }\end{array}$} & \multicolumn{3}{|c|}{ Value } & \multirow[t]{2}{*}{ Closeness } & \multicolumn{3}{|c|}{ Value } & \multirow[t]{2}{*}{ Betweenness } & \multirow[t]{2}{*}{ Value } \\
\hline & & $\begin{array}{c}\text { Out } \\
\text { degree }\end{array}$ & $\begin{array}{c}\text { In } \\
\text { degree }\end{array}$ & $\begin{array}{c}\text { All } \\
\text { degree }\end{array}$ & & $\begin{array}{c}\text { in } \\
\text { closeness }\end{array}$ & $\begin{array}{c}\text { out } \\
\text { closeness }\end{array}$ & $\begin{array}{c}\text { all } \\
\text { closeness }\end{array}$ & & \\
\hline 1 & PSS & 16 & 7 & 23 & SB & 0.29 & 0.87 & 0.91 & $\mathrm{AC}$ & 0.30 \\
\hline 2 & $\mathrm{SB}$ & 18 & 4 & 22 & PSS & 0.45 & 0.80 & 0.88 & OCC & 0.29 \\
\hline 3 & $\cos$ & 11 & 8 & 19 & cos & 0.46 & 0.62 & 0.81 & PSS & 0.23 \\
\hline 4 & EWP & 10 & 8 & 18 & VES & 0.68 & 0.22 & 0.75 & PSD & 0.13 \\
\hline 5 & AFAS & 10 & 7 & 17 & AFAS & 0.38 & 0.60 & 0.75 & VES & 0.10 \\
\hline
\end{tabular}

three vertices with the largest values of $0.30,0.29$, and 0.23 respectively. This indicates that AC, OCC and PSS play the role of intermediary in the interaction between the others in the SPSN (Freeman 1977). In SPSN, AC determines the accessibility of individuals to the subway physical system. Both subway construction and operation should be undertaken by professionals, and $\mathrm{AC}$ can effectively prevent the risks taken by an unauthorized person. OCC is in charge of the daily operation of SPSN. Data collected from the SPSN are reported to OCC for decision-making, and then the instructions are sent out for the operation of the subway system. Since PSS provides the power for the entire subway system, any failure in any subsystem that leads to the function loss of PSS will surely cut off the power for other subsystems.

The network analysis of SPSN demonstrates the dependence and interdependence of its subsystem in lifecycle safety performance. Degree distribution, closeness and betweenness were calculated to illustrate the centrality of the network. The results are shown in Table 5.

The results show that Station Building (SB), Communication System (COS), Automation Fire Alarm System (AFAS) and Vehicle System (VES) rank at the top five in degree distribution; SB and PSS have the highest closeness value, and the values of Access Control (AC), Operation Control Center (OCC) and PSS are the top three in betweenness. Among these subsystems, Power Supply System (PSS) ranks in the top 3 in all three parameters, while

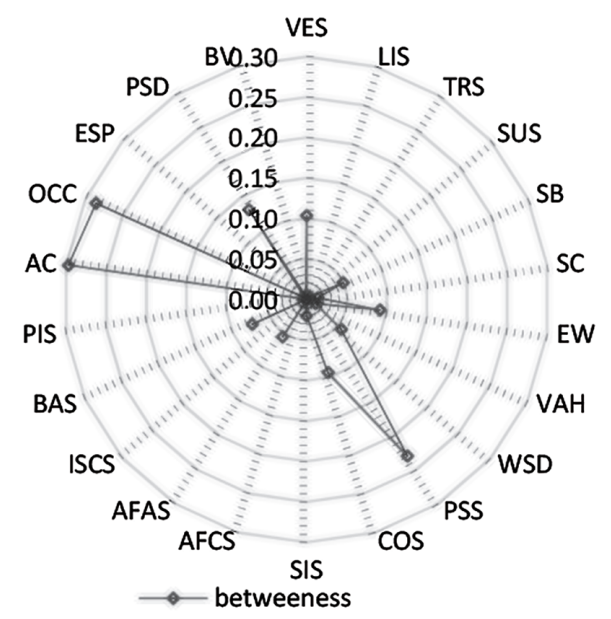

Figure 12. Betweenness centrality of nodes in the SPSN
Station Building (SB), Communication System (COS), Automation Fire Alarm System (AFAS), and Vehicle System (VES) appear more than once in the table. It can be concluded that the safety performance of PSS, SB, COS, AFAS, and VES have a greater influence on other subsystems in SPSN, while AC, OCC and PSS play the significant role of intermediary in hazards propagation.

\section{Discussion}

To validate DFS concept in lifecycle subway projects in China, the classification model proposed by Behm (2005) is modified to build the subway design-incident classification model (SDICM) by introducing three precursors, which helps to improve the efficiency and accuracy of the classification process. The ICA shows that 236 out of $442(53.3 \%)$ collected cases were linked to DFS using the SDICM. The result confirms that decisions made upstream have a significant influence on the lifecycle safety performance, and some hazards can be designed out of subway projects. It is crucial to implement DFS in order to improve the lifecycle safety performance of subway projects. Results from the ICA show that $36.1 \%$ of incidents that occurred in the construction phase were related to DFS, which is lower than the $42 \%$ reported in previous quantified research conducted by Behm (2005) and 47\% reported by Gibb et al. (2004). In China, subway projects are considered as critical infrastructure, thus, the design activities together with the construction, operation, and maintenance phases are given strictly supervision by the government. On the other hand, the emerging of advanced ICTs, collaborative projects delivery methods as well as new concept (i.e., DFS) has improved the designers' work over time (Zhou et al. 2014; Karakhan, Gambatese 2017), which may result the downward trend of DFS-related incidents rate in this paper. In addition to the construction phases, this paper also studied the impact of DFS on the operation phase. In total, $69.9 \%$ of incidents occurring in the operation phase were linked to DFS. This means that DFS has a greater influence on subway operation than construction from the perspective of both number of incidents and casualties. This is because many of the design activities are focused on the operation phase, and the duration of subway operation stage is much longer than the construction stage. 
Network analysis denotes the strong interdependence of subsystems in lifecycle safety performance. Failures occurring in any of the subway subsystems may quickly affect other subsystems and finally lead to the failure of the entire system. Statistics show that Power Supply System (PSS), Station Building (SB), and Vehicle system (VES) are closer to other subsystems in safety performance, which means these subsystems can directly affect or be affected by other subsystems in a subway's physical system. Meanwhile, Access Control (AC), Operation Control Center (OCC), and PSS play significant roles in failures propagating between different subsystems according to network analysis. Failures occurring in one specific subsystem may quickly spread to the whole network through these subsystems. The findings of network analysis provide opportunities to block the propagation of hazards by offering a safer and more reliable design of the identified subsystems. Meanwhile, network analysis reveals the features of subway physical systems in safety performance as well as the safety performance of each subsystem. Understanding the characteristics of the system, designers could enhance subway lifecycle safety performance not only by improving the design work of each subsystem isolatedly but also through the consideration of them as a whole system.

According to results of ICA, Station Building (SB), Section construction (SC), Vehicle system (VES), Platform Screen Door (PSD), Power Supply System (PSS), and Signal System (SIS) are identified with the highest incident rates in total cases among all the subsystems. The results of the network analysis are consistent with the ICA. Subsystems with higher incident rates in the ICA are verified in the network analysis with higher importance in safety performance. Therefore, these subsystems are extremely critical for lifecycle safety performance of subway projects, and measures should be taken to ensure the safety performance of these subsystems by the designers as well as researchers. In the ICA, the number of DFS-related cases was almost the same within the total cases, as shown in Figure 8, which means that hazards occurring in PSD could be avoided at a large extent if DFS was implemented. In the network analysis, the value of the degree distribution and the closeness of PSD are lower than average, which indicates lower safety interdependence in the subway's physical network. It can be concluded from the ICA and network analysis, incidents occurring in PSD are mostly caused by failures occurring within the subsystem itself, and with design improvement, the number of incidents may drop dramatically. Thus, the adoption of DFS in subsystems like PSD, which have a high incident rate but lower safety interdependence, will improve subway lifecycle safety management effectively and immediately. However, despite the proportions of DFS-related incidents in total cases being lower than other subsystems, the number of incidents in SB and SC are still high, and compared to the duration of the subway operation phase, the construction phase is relatively shorter. The number of accidents occurred in this period is high which indicates construc- tion phases is more dangerous. Therefore, the construction phase should also be given special attention during the design phase.

\section{Conclusions}

Nowadays, subways are rather than alternative options in urban transportation systems, but also a symbol of the city competence. Therefore, numerous cities in China are pursuing the development of subways. While more subway projects are under construction and in operation, accidents happened in jobsites have led to great loss of human lives and properties, safety management of lifecycle subway projects is crucial to both economic growth and social stability. DFS provides a new means to promote safety management earlier, not only for subway projects but also the entire industry. This paper analyzed the collected incidents occurred in lifecycle subway projects, and incidents linked to design work were identified using SDICM. Unlike the traditional construction projects, lifecycle subway projects include numerous subsystems which constitute the SPSN. Instead of modelling by structural decomposition, safety performance of SPSN was studied with the help of network theory by functional abstraction of SPSN. Results of the empirical approach by conducting ICA show that design work upstream has a significant influence on subway project lifecycle safety management. Compared with the construction phase $(36.1 \%)$, safety performance in the operation phase $(69.9 \%)$ is more prone to being affected by design activities. While the collected data show the incidents happened in the operation phase are making up the majority of the all the incidents in recent years, and as depicted in Figure1, the numbers of cities with subways in operation and the mileages of subway in operation are gradually increasing, the adoption of DFS is essential for subway projects as well as other projects with the same characteristics. Results of ICA also show the difference of each subsystem in safety performance, and subsystems with high incident rate were identified. Theses difference obtained coincide with network analysis. Subsystems with high incidents rate are identified to be more vulnerable in SPSN.

The results of network analysis help to improve the understanding of subway design work for safety management. By studying the characteristics of SPSN, PSS, SB, COS, AFAS, and VES are identified by their great influence on other subsystems in the SPSN; meanwhile, subsystems such as AC, OCC and PSS play a significant role of intermediary in hazards propagation. These subsystems should be given prior consideration during the implementation of DFS.

This paper extends the validation of DFS concept to lifecycle safety management of subway project, and it shows that DFS has great potential in promoting subway lifecycle safety management. Eliminating hazard at the design phase will surely improve the lifecycle safety performance of subway projects at lower costs. With the 
identified subsystems, designers and researchers can take measures to enhance lifecycle safety performance of subway projects. For example, to simulate the construction and operation of subway projects with the advanced technologies during the design phase. In fact, lifecycle subway safety management is a cross-disciplinary research area more than a solely technical issue, future researches could conduct from other aspects such as social-technical aspect. Besides, the subway's physical system is more complex than depicted in this paper; a detailed analysis of an SPSN in lifecycle safety management is needed in the future, and the effect of DFS should be recorded in jobsites for future research.

\section{Funding}

This work was supported by the National Natural Science Foundation of China [grand No. 51578144, 71472037, and 71671042]; the Postgraduates' Science and Innovation Foundation of Jiangsu Province [grand No. KYLX_0206]; and Priority Academic Program Development of Jiangsu Higher Education Institutions.

\section{Disclosure statement}

All the authors have no conflict of interest.

\section{References}

Bavelas, A. 1948. A mathematical model for group structures, Human Organization 7(3): 16-30. https://doi.org/10.17730/humo.7.3.f4033344851g1053

Behm, M. 2005. Linking construction fatalities to the design for construction safety concept, Safety Science 43: 589-611. https://doi.org/10.1016/j.ssci.2005.04.002

Carter, G.; Smith, S. D. 2006. Safety hazard identification on construction projects, Journal of Construction Engineering and Management 132: 197-205. https://doi.org/10.1061/(ASCE)0733-9364(2006)132:2(197)

Coats, T.; Walter, D. 1999. Effect of station design on death in the London Underground: observational study, BMJ 319: 957-957. https://doi.org/10.1136/bmj.319.7215.957

Deng, Y.; Li, Q.; Lu, Y. 2015. A research on subway physical vulnerability based on network theory and FMECA, Safety Science 80: 127-134. https://doi.org/10.1016/j.ssci.2015.07.019

Ding, L.; Yu, H.; Li, H.; Zhou, C.; Wu, X.; Yu, M. 2012. Safety risk identification system for metro construction on the basis of construction drawings, Automation in Construction 27: 120-137. https://doi.org/10.1016/j.autcon.2012.05.010

Ding, L.; Zhou, C. 2013. Development of web-based system for safety risk early warning in urban metro construction, Automation in Construction 34: 45-55.

https://doi.org/10.1016/j.autcon.2012.11.001

Driscoll, T. R.; Harrison, J. E.; Bradley, C.; Newson, R. S. 2008. The role of design issues in work-related fatal injury in Australia, Journal of Safety Research 39: 209-214.

https://doi.org/10.1016/j.jsr.2008.02.024

Fouracre, P.; Dunkerley, C.; Gardner, G. 2003. Mass rapid transit systems for cities in the developing world, Transport Reviews 23: 299-310. https://doi.org/10.1080/0144164032000083095
Freeman, L. C. 1977. A set of measures of centrality based on betweenness, Sociometry 40(1): 35-41.

https://doi.org/10.2307/3033543

Gambatese, J. A. 1998. Liability in designing for construction worker safety, Journal of Architectural Engineering 4: 107-112. https://doi.org/10.1061/(ASCE)10760431(1998)4:3(107)

Gambatese, J. A.; Behm, M.; Hinze, J. W. 2005. Viability of designing for construction worker safety, Journal of Construction Engineering and Management 131: 1029-1036.

https://doi.org/10.1061/(ASCE)0733-9364(2005)131:9(1029)

Gambatese, J. A.; Behm, M.; Rajendran, S. 2008. Design's role in construction accident causality and prevention: Perspectives from an expert panel, Safety Science 46: 675-691. https://doi.org/10.1016/j.ssci.2007.06.010

Gambatese, J. A.; Dunston, P. S. 2003. Designer consideration of project lifecycle performance, in Construction Research Congress: Wind of Change: Integration and Innovation, 2003, 1-8.

Gambatese, J. A.; Hinze, J. W.; Haas, C. T. 1997. Tool to design for construction worker safety, Journal of Architectural Engineering 3: 32-41. https://doi.org/10.1061/(ASCE)1076-0431(1997)3:1(32)

Gambatese, J.; Hinze, J. 1999. Addressing construction worker safety in the design phase: Designing for construction worker safety, Automation in Construction 8: 643-649. https://doi.org/10.1016/S0926-5805(98)00109-5

Gibb, A. 2002. Safety in design: A European/UK view, in Proc. of the $12^{\text {th }}$ Annual Construction Safety \& Health Conference, 2002, 552-557.

Gibb, A.; Haslam, R.; Hide, S.; Gyi, D. 2004. The role of design in accident causality, in Designing for Safety and Health in Construction: Proceedings, Research and Practice Symposium. Eugene, OR: UO Press.

Hadikusumo, B.; Rowlinson, S. 2004. Capturing safety knowledge using design-for-safety-process tool, Journal of Construction Engineering and Management 130: 281-289. https://doi.org/10.1061/(ASCE)0733-9364(2004)130:2(281)

Hallowell, M. R.; Gambatese, J A. 2009. Qualitative research: Application of the Delphi method to CEM research[J], Journal of Construction Engineering and Management 136(1): 99-107. https://doi.org/10.1061/(ASCE)CO.1943-7862.0000137

Hallowell, M. R.; Hansen, D. 2016. Measuring and improving designer hazard recognition skill: Critical competency to enable prevention through design, Safety Science 82: 254-263. https://doi.org/10.1016/j.ssci.2015.09.005

Haslam, R. A.; Hide, S. A.; Gibb, A. G.; Gyi, D. E.; Pavitt, T.; Atkinson, S.; Duff, A. 2005. Contributing factors in construction accidents, Applied Ergonomics 36: 401-415. https://doi.org/10.1016/j.apergo.2004.12.002

Hinze, J. 1997. Construction safety[M]. Prentice Hall.

Hinze, J.; Wiegand, F. 1992. Role of designers in construction worker safety, Journal of Construction Engineering and Management 118: 677-684.

https://doi.org/10.1061/(ASCE)0733-9364(1992)118:4(677)

Hollnagel, E. 2008. Risk + barriers = safety?, Safety Science 46(2): 221-229. https://doi.org/10.1016/j.ssci.2007.06.028

Karakhan, A. A.; Gambatese, J. A. 2017. Identification, quantification, and classification of potential safety risk for sustainable construction in the United States, Journal of Construction Engineering and Management 143(7): 04017018. https://doi.org/10.1061/(ASCE)CO.1943-7862.0001302

Korman, R. 2001. Wanted: new ideas. Panel ponders ways to end accidents and health hazards, Engineering News-Record 247: 26-29. 
Krysinska, K.; De Leo, D. 2008. Suicide on railway networks: epidemiology, risk factors and prevention, Australian \& New Zealand Journal of Psychiatry 42: 763-771.

https://doi.org/10.1080/00048670802277255

Kyriakidis, M.; Hirsch, R.; Majumdar, A. 2012. Metro railway safety: An analysis of accident precursors, Safety Science 50: 1535-1548. https://doi.org/10.1016/j.ssci.2012.03.004

Li, J. S.; Chow, W. 2003. Numerical studies on performance evaluation of tunnel ventilation safety systems, Tunnelling and Underground Space Technology 18: 435-452. https://doi.org/10.1016/S0886-7798(03)00023-3

Lopez, R.; Love, P. E.; Edwards, D. J.; Davis, P. R. 2010. Design error classification, causation, and prevention in construction engineering, Journal of Performance of Constructed Facilities 24: 399-408.

https://doi.org/10.1061/(ASCE)CF.1943-5509.0000116

Lortie, M.; Rizzo, P. 1998. The classification of accident data, Safety Science 31: 31-57.

https://doi.org/10.1016/S0925-7535(98)00053-8

Lu, Y.; Hinze, J.; Li, Q. 2011. Developing fuzzy signal detection theory for workers' hazard perception measures on subway operations, Safety Science 49: 491-497.

https://doi.org/10.1016/j.ssci.2010.11.008

Lu, Y.; Li, Q.; Xiao, W. 2013. Case-based reasoning for automated safety risk analysis on subway operation: Case representation and retrieval, Safety Science 57: 75-81.

https://doi.org/10.1016/j.ssci.2013.01.020

Mackenzie, J.; Gibb, A.; Bouchlaghem, N. 2000. Communication: the key to designing safely. European Construction Institute.

Manuele, F. A. (Ed.) 1997. On the practice of safety. $3^{\text {rd }} \mathrm{ed}$. Willey Interscience.

Martínez-Aires, M. D.; Rubio Gámez, M. C.; Gibb, A. 2015. The impact of occupational health and safety regulations on prevention through design in construction projects: Perspectives from Spain and the United Kingdom, Work 53: 181-191. https://doi.org/10.3233/WOR-152148

National Bureau of statistics of China. 2016. China statistical yearbook 2016.

Qi, J.; Issa, R.; Hinze, J.; Olbina, S. 2011. Integration of safety in design through the use of building information modelling, in International Workshop on Computing in Civil Engineering 2011, 19-22 June 2011, Miami, Florida, United States.

Rasmussen, J. 1997. Risk management in a dynamic society: a modelling problem, Safety Science 27(2-3): 183-213. https://doi.org/10.1016/S0925-7535(97)00052-0

Sabidussi, G. 1966. The centrality index of a graph, Psychometrika 31: 581-603. https://doi.org/10.1007/BF02289527

Seo, J. W.; Choi, H. H. 2008. Risk-based safety impact assessment methodology for underground construction projects in Korea, Journal of Construction Engineering and Management 134: 72-81. https://doi.org/10.1061/(ASCE)0733-9364(2008)134:1(72)

Suraji, A.; Duff, A. R.; Peckitt, S. J. 2001. Development of causal model of construction accident causation, Journal of Construction Engineering and Management 127: 337-344. https://doi.org/10.1061/(ASCE)0733-9364(2001)127:4(337)

Swuste, P. 2008. "You will only see it, if you understand it" or occupational risk prevention from a management perspective, Human Factors and Ergonomics in Manufacturing \& Service Industries 18: 438-453. https://doi.org/10.1002/hfm.20101

Szymberski, R. T. 1997. Construction project safety planning, Tappi Journal, USA.
Taiebat, M.; Ku, K. 2011. Tuning up the core of hazard identification: How to improve stimulated thinking for safety in design, in Proc. of The $47^{\text {th }}$ ASC Annual International Conference, 2011.

Turner, B. A. 1989. Accidents and nonrandom error propagation, Risk Analysis 9(4): 437-444. https://doi.org/10.1111/j.1539-6924.1989.tb01254.x

Tymvios, N.; Gambatese, J. A. 2016. Direction for generating interest for design for construction worker safety - A Delphi study, Journal of Construction Engineering and Management 142: 04016024.

https://doi.org/10.1061/(ASCE)CO.1943-7862.0001134

Wan, X.; Li, Q.; Yuan, J.; Schonfeld, P. M. 2015. Metro passenger behaviors and their relations to metro incident involvement, Accident Analysis \& Prevention 82: 90-100.

https://doi.org/10.1016/j.aap.2015.05.015

Wang, H.-d.; Pan, K.; Jiang, F.-d. 2007. AHP-based hazards analysis of urban subway operation safety and preventive countermeasures, Journal of the China Railway Society 29(2).

Weinstein, M.; Gambatese, J.; Hecker, S. 2005. Can design improve construction safety?: Assessing the impact of a collaborative safety-in-design process, Journal of Construction Engineering and Management 131: 1125-1134. https://doi. org/10.1061/(ASCE)0733-9364(2005)131:10(1125)

WorkCover. 2001. CHAIR safety in design tool (CHAIR - Construction Hazard Assessment Implication Review). Sydney, Australia.

Zhang, L.; Skibniewski, M. J.; Wu, X.; Chen, Y.; Deng, Q. 2014. A probabilistic approach for safety risk analysis in metro construction, Safety Science 63: 8-17.

https://doi.org/10.1016/j.ssci.2013.10.016

Zhang, X.; Deng, Y.; Li, Q.; Skitmore, M.; Zhou, Z. 2016. An incident database for improving metro safety: The case of Shanghai, Safety Science 84: 88-96.

https://doi.org/10.1016/j.ssci.2015.11.023

Zhong, M.; Shi, C.; Tu, X.; Fu, T.; He, L. 2008. Study of the human evacuation simulation of metro fire safety analysis in China, Journal of Loss Prevention in the Process Industries 21: 287-298. https://doi.org/10.1016/j.jlp.2007.08.001

Zhou, Z.; Goh, Y. M.; Li, Q. 2015. Overview and analysis of safety management studies in the construction industry, Safety Science 72: 337-350. https://doi.org/10.1016/j.ssci.2014.10.006

Zhou, Z.; Irizarry, J.; Li, Q. 2014. Using network theory to explore the complexity of subway construction accident network (SCAN) for promoting safety management, Safety Science 64: 127-136. https://doi.org/10.1016/j.ssci.2013.11.029

Zhou, Z.; Li, Q.; Wu, W. 2011. Developing a versatile subway construction incident database for safety management, Journal of Construction Engineering and Management 138: 1169-1180. https://doi.org/10.1061/(ASCE)CO.1943-7862.0000518

Zou, P. X.; Li, J. 2010. Risk identification and assessment in subway projects: case study of Nanjing Subway Line 2, Construction Management and Economics 28: 1219-1238. https://doi.org/10.1080/01446193.2010.519781

Zou, Y.; Kiviniemi, A.; Jones, S. W. 2017. A review of risk management through BIM and BIM-related technologies, Safety Science 97: 88-98. https://doi.org/10.1016/j.ssci.2015.12.027 